\title{
Globe
}

Revue internationale d'études québécoises

\section{Zilá Bernd : Américanité et mobilités transculturelles, Québec, Les Presses de l’Université Laval, 2009}

\section{Licia Soares de Souza}

Volume 12, numéro 2, 2009

URI : https://id.erudit.org/iderudit/1000716ar

DOI : https://doi.org/10.7202/1000716ar

Aller au sommaire du numéro

Éditeur(s)

Globe, Revue internationale d'études québécoises

ISSN

1481-5869 (imprimé)

1923-8231 (numérique)

Découvrir la revue

Citer ce compte rendu

Soares de Souza, L. (2009). Compte rendu de [Zilá Bernd : Américanité et mobilités transculturelles, Québec, Les Presses de l’Université Laval, 2009]. Globe, 12(2), 204-207. https://doi.org/10.7202/1000716ar d'utilisation que vous pouvez consulter en ligne.

https://apropos.erudit.org/fr/usagers/politique-dutilisation/ 
"moment mémoire" ne semble pas prêt de s'éteindre dans les travaux universitaires. Les chercheurs pourront trouver dans cet ouvrage les mises en garde qui s'imposent.

Anne Caumartin

Collège militaire royal de Saint-Jean

\section{Zilá Bernd \\ Américanité et mobilités transculturelles \\ Québec, Les Presses de l'Université Laval, 2009.}

Sans vouloir tomber dans l'enflure verbale, on peut affirmer que ce livre est sans contredit une belle réussite pour les études comparées en sciences humaines et pour la dynamisation des relations Québec-Brésil. Qui de mieux que Zilá Bernd pour nous guider dans cet univers de thématiques qui nous séduisent depuis longtemps, comme elle le dit, telles que l'américanité, les passages transculturels dans les Amériques et les figurations mythiques qui peuplent les imaginaires collectifs américains?

Les articles ont été rédigés entre 2002 et 2008 et témoignent d'un travail de recherche que l'auteure dirige, regroupant plusieurs professeurs canadiens, brésiliens et français qui s'intéressent aux perspectives comparées transaméricaines. Dans sa présentation, Bernd retrace les étapes fondamentales de ce travail d'équipe, tout en mettant en relief l'apport de ses colloques et publications. La création du groupe MYSAM (Mythes et Sociétés des Amériques) par Bernard Andrès et Gérard Bouchard, par exemple, a conduit à des réflexions cruciales sur les modes de migration des mythes européens et africains dans les pays des Amériques, produisant des synthèses imaginaires significatives. Ce projet a favorisé la rencontre de plusieurs collègues autour d'un autre projet que Bernd a mis en chantier. Le Dicionário de Figuras e Mitos Literários das Américas (2007) a réuni 80 chercheurs du nord et du sud des Amériques qui se sont consacrés à montrer comment les mythes d'origine gréco-latine se sont transformés pendant leurs traversées dans les terres du Nouveau Monde. Force est de constater qu'un tel dictionnaire constitue un ouvrage inédit qui a pu mettre en lumière des mythes des Amériques que les dictionnaires littéraires reconnus n'ont jamais pris en considération.

L'auteure présente ainsi des travaux issus d'un dialogue de 30 ans avec ses collègues "transaméricains", tout en montrant l'importance de 
quelques associations et conseils de recherche pour permettre la vigueur des échanges: l'ABECAN (Association brésilienne d'études canadiennes), l'ICCS-CIEC (Conseil international d'études canadiennes), le groupe de travail de l'ANPOLL (Association nationale de recherche en langue et littérature), le $\mathrm{CNPq}$ (Conseil national de recherche scientifique et technologique, à Brasília) et l'Université Fédérale de Rio Grande do Sul. Elle rappelle également le rôle prépondérant que quelques revues ont joué et continuent de jouer pour l'intensification des débats passionnants entre les chercheurs de différentes lattitudes: Interfaces Brasil Canada et Canadart au Brésil, Voix et Images, au Québec, et la Revue internationale d'études canadiennes, au Canada.

Les articles présentés dans l'ouvrage sont répartis en trois chapitres qui traitent du contexte desdites relations culturelles transaméricaines. Le premier s'intitule "Réflexions théoriques": il se concentre sur les parcours conceptuels de l'américanité et de la transculturation, interroge le rôle des passeurs culturels et réfléchit à la désuétude de l'idée de littérature nationale.

En portugais, l'américanité possède plusieurs variantes - americanidad, americanidade, americanisation - aptes à souligner les déplacements et les transferts de sens liés aux questions identitaires, qui vont au-delà des nationalités, des genres et des ethnies, émergeant au sein de l'extrême hétérogénéité du continent américain. Le concept a suivi plusieurs itinéraires significatifs, au Brésil, au Québec, aux Antilles, reflétant les actes de passage qui ont déterminé le conflit inaugural propre aux sujets américains : l'émergence d'un monde hybride bâti à partir de la rencontre de peuples différents. Quant au concept de transculturation (connu comme transculturación depuis le célèbre livre de Fernando Ortiz, paru en 1940), il renvoie aux processus d'échanges qui se sont développés dans les deux sens, lors de la rencontre de cultures distinctes, et qui ont donné naissance à une culture hybride originale et jamais achevée. Bernd montre également comment le concept devient, au Québec, la transculture (le terme transculturation n'existant pas en français) qui, même en ne rendant pas l'idée d'un processus inachevé de formation culturelle, demeure au cœur de la problématique relative aux pratiques symboliques des minorités ethniques et culturelles, associées aux dé/re-territorialisations, à l'exil et aux déracinements.

Dans ce contexte, le dialogue entre les différentes universités des Amériques a fait de leurs chercheurs des passeurs culturels qui ont développé des méthodes comparatistes pour aborder les différentes pratiques culturelles issues des affrontements entre les cultures européennes, celles des colonisateurs, et les cultures autochtones, celles des colonisés. C'est ainsi que, 
devant l'intense mobilité territoriale et culturelle, classifier les littératures selon leur appartenance à une seule nation est devenu quelque chose de difficile et même de compliqué. Les littératures américaines doivent être reconnues comme appartenant à une culture hybride, située à un carrefour culturel.

Le second chapitre, "Lectures transversales des littératures des Amériques", propose de réfléchir aux similitudes et aux différences entre les enjeux identitaires québécois et brésiliens. Une première partie, "Brésil/Québec: itinéraire et traversées", est une analyse d'œuvres d'écrivains des deux pays: Sergio Kokis et Dany Laferrière pour le corpus québécois, Mário de Andrade et João Ubaldo Ribeiro pour le corpus brésilien. L’objectif de l'auteure est de montrer comment les voyages et les faits transculturels représentés par ces quatre romanciers au cours de leurs déplacements fonctionnent comme une métonymie de la construction/déconstruction identitaire des deux nations.

Une seconde partie, "Métamorphoses comme figurations de l'américanité", met en parallèle Life of Pi (2002) de l'écrivain canadien Yann Martel et Max et les Félins (1981) de l'écrivain brésilien Moacyr Sclíar. Il s'agit d'un examen des convergences existant entre les deux ouvrages et des figures de l'américanité qui se ressemblent dans l'optique d'une thématique de la traversée de l'océan. Le voyage inaugural de Christophe Colomb y est métaphorisé; les bateaux de sauvetage qui permettent aux adolescents d'arriver au Canada et au Brésil renvoient à l'arche de Noé, mythe du recommencement et de la restauration cyclique, selon Bernd.

La troisième partie de ce chapitre, "Figures et mythes de l'américanité" est une analyse comparée d'un roman de Gérard Bouchard, Mistouk (2002) et d'un roman brésilien, Maíra (1981), de Darcy Ribeiro. Ces deux livres exploitent les mythes et les figures de l'américanité en ce qu'ils sont construits à partir de voyages et de traversées qui symbolisent les quêtes identitaires.

Le dernier chapitre, intitulé "Les Amériques mythiques", est divisé en trois parties: "Imaginaires collectifs et mobilités (trans)culturelles", "Franco(poly)phonies des Amériques: l'(ex)empire (colonial) contreattaque ", et "Pôles et convergences: l'inscription littéraire des mythes américains". Bernd met l'accent, dans la première partie, sur l'approche théorique qui a présidé à la composition du Dictionnaire de figures et mythes littéraires des Amériques. Le postulat initial pour la constitution des entrées partait du principe que les nations des Amériques ont dû affronter des problèmes similaires lors de la conquête, comme l'obligation de s'exprimer 
dans la langue de l'autre, le colonisateur, et de devoir forger leurs pratiques culturelles avec cette nouvelle langue. Les concepts de transfert culturel et de mobilité, ainsi que celui de créolisation, peuvent contribuer à la compréhension des transformations des mythes de l'américanité dans les territoires distincts des Amériques.

La seconde partie du dernier chapitre décrit l'importance des études francophones dans les universités brésiliennes. La troisième partie propose l'analyse du best-seller brésilien Le colonel et le loup-garou, publié en 1964 et traduit en plusieurs langues, dont le français et l'allemand. Bernd montre comment la culture populaire, par son côté merveilleux, transforme les mythologies importées par les colonisateurs, tout en façonnant une nouvelle vision cosmique propre aux terres américaines.

Finalement, l'auteure atteste que l'américanité renvoie à une conception assez précise des mobilités " trans" et peut donner lieu à des travaux fructueux en littérature comparée, capables de mettre en relation des confluences imaginaires d'ensembles littéraires issus du continent américain, sans qu'on ait à se référer aux productions littéraires européennes.

Licia Soares de Souza, Université de l'État de Bahia (Brésil)

\section{Félix Bouvier et Michel Sarra-Bournet (dir.) L'enseignement de l'bistoire au début du XXI' siècle au Québec Québec, Septentrion, 2008.}

Le nouveau programme d'enseignement de l'histoire au secondaire a fait couler beaucoup d'encre; il y a longtemps qu'un cours d'histoire au secondaire n'a occasionné autant de réflexions, voire de passions. Devant le nombre impressionnant de commentaires, de lettres ouvertes ou d'analyses, il est parfois difficile de s'y retrouver, chacun y allant de ses opinions exprimées dans un jargon peu accessible au "commun des mortels". Cet ouvrage dirigé par Félix Bouvier et Michel Sarra-Bournet propose une sorte de bilan de ces discussions. Douze articles regroupés de manière thématique composent ce recueil qui rappelle quelques-unes des questions importantes de ce débat. D'autres publications, comme un numéro spécial du Bulletin d'histoire politique (janvier 2007), ont déjà soulevé d'intéressantes discussions, mais cette fois-ci, la Société des professeurs d'histoire du Québec 